\title{
Analysis of the Normal Transition Event of the LHD Helical Coils
}

\author{
Nagato Yanagi, Shinsakı Imagawa, Toshiyuki Mito, Akifumi Iwamoto, Hirotaka Chikaraishi, \\ Shinji Hamaguchi, Arata Nishimura, Takashi Satow, Yukio Nakamura, Sadao Satoh, \\ Osamu Motojima, and the LHD Group \\ National Institute for Fusion Science, 322-6 Oroshi-cho, Toki, Gifu 509-5292, Japan
}

Andrew V. Gavrilin

Kurchatov Institute, 123182, Moscow, Russia

\begin{abstract}
Normal transitions and a subsequent quench were experienced with the pool-cooled helieal coils of the Large ILelical Device (LIID) during its excitation test. Although the initiated normal me once started to recover, a dis ruptive transverse propagation followed and triggered an emergency. discharging program. The eryngenic stabllity of the composite-type superconductor has been studied by sample experiments as well as by mimerical calculations. Dne to the rather long magnetic diffusion time constunt in the pure aluminum stabilizer, transient stability of the conductor scems to play an important role for driving finte propagation of a normal a)ne. The cause of the final quencli is also disenssed from the viewpoint of cooling deterioration due to a possible accumalation of helium bubhles.
\end{abstract}

\section{INTRODUCTION}

The constunction of the Large Helical Device (LHD) has been successfilly completed with a filly superconducting coil system [i], and fusion-relevant plastma experiments are ongoing with a heliotron magnetic configuration that roquires no toroidal plasma current [2]. The one pair of two helical coils ( $\mathrm{YI}$ and $\mathrm{H} 2$ ) have a major radius of $3.9 \mathrm{~m}$ and are poolcooled with $4.4 \mathrm{~K}$ liquid helium in the present Phase I condition, In the Phase II program of LHD, I.8 K Holium II will be supplied and the maximum stored magnetic energy will reach up to $1.6 \mathrm{GJ}$ with a foroidal magnetic field of $4 \mathrm{~T}$.

Fach of the two helical coils consists of thre independent blocks, H-I (imer), H-M (middle) and ILO (outer), and the whole windings are contained in thick stainless steel coilaans. The corresponding blocks of the two coils are connected in series to three individual DC power supplics through six superconducting bus-lines. For quench detection, balance voltages are measured between each corresponding block. For examplo, the $\mathrm{H}-\mathrm{I}$ balance voltage is given by subtracting the terminal voltage of the I-I2-I block fiom that of the H1-I block in a quench detection circuit.

Mannseript teceived September 27, 1999.

V-mail : yamagiolsl[D, nits.ne.jp, Phone: $+81-572-58-2126$, Fax : $-81-572$ $58-2616$
During the excitation tests of LHD aiming at a nominal toroidal feld of $3 \mathrm{~T}$ at $4.4 \mathrm{~K}$, normal transitions occutred at the innermost layers of the helical coils, and a coil quench followed at the toroidal field of $2.75 \mathrm{~T}$. The details of this entire event including the general excitation characteristics of the helical coils are described in [3]. In this paper, the cryogenic stability of the winding conductor is discussed based on sample conductor tests and comparison with numerical calculations for investigating the cause of the notmal transition. The final quench event is also cxamined from the viewpoint of cooling deterioration, based on the experiences obtained with R\&D coils,

\section{I3. THL NORMAL TRANSITION EVEN'T}

Fig. I shows the waveforms of the measured balance voltage signals for the three blocks of the helical coils during the quench event, A transport current of $11.45 \mathrm{kA}$ was being supplied to ench block before the emergency discharge, $A s$ is infered fiom the positive rise of the III brance voltage (at $t \approx$

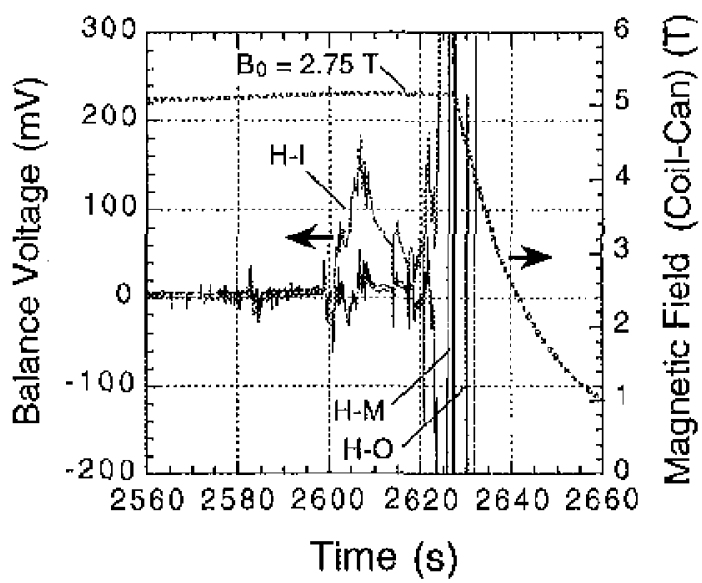

Fig, Wayeforms ol the balance voltage signals measured tor the three blocks althe helical colls, during a quench evont at a toroidal licld of 2.75 'é. Magnetic lictd neasured by a llall probe on die coil-can is also shown. 
$2600 \mathrm{~s})$ in Fig. I, a normal zone was initiated in the $\mathrm{Hl}-\mathrm{I}$ block. According to the normal conducting resistivity of the superconductor obtained by previous sample tests, the initiatcol normal zone can be estimated to have developed over approximately $15 \mathrm{~m}$ and then if started to shrink (at $t \approx 2607$ s). It might be reasonable to consider that a nomal wone was initiated at the innemost layer of HI-J block, where the magnetic field becomes the highest. According to the spike signals seen on the balance voltages, the initiation of nomal zones sectnd to be brought on by mechanical disturbances due to the large electromagnetic force acting on the windings.

Despite the gradual recovering process of the normal zone, sudden and simultaneous increases of the batance voltages occurred for all three blocks (at $\mathrm{t} \approx 2621 \mathrm{~s}$ ), which finally triggered the quench detectos. Then the emergency discharging process went into action (at $t=2627 \mathrm{~s}$ ) as it was programmed to do. Subsequently, the entire superconducting coil system, including the poloidal coils and bus-lines, were safely discharged with a time constant of $20 \mathrm{~s}$, together with the proper action of the cryogenic system [4].

\section{STABILTY CIMRACTLRISITCS OF THI HeLLTC COLL SUPLERCONJJLCTOR}

\section{A. Stability Test Results with Conductor Samples.}

lior the pool-cooled helical coil windings, a NbTi/Cu composite-lype superconductor is used wilh a high pultity aluminum stabilizer and a copper jackot. One of the key foatures of this conductor (size: $12.5 \mathrm{~mm} \times 18 \mathrm{~mm}$, nominal current: $13.0 \mathrm{k} \Lambda$ at $6.9 \mathrm{~T}$ ) is that CuNi is used, instead of conventional copper, as the clad matcrial around the pure aluminum core to reduce the parasitic Hall curtent generation

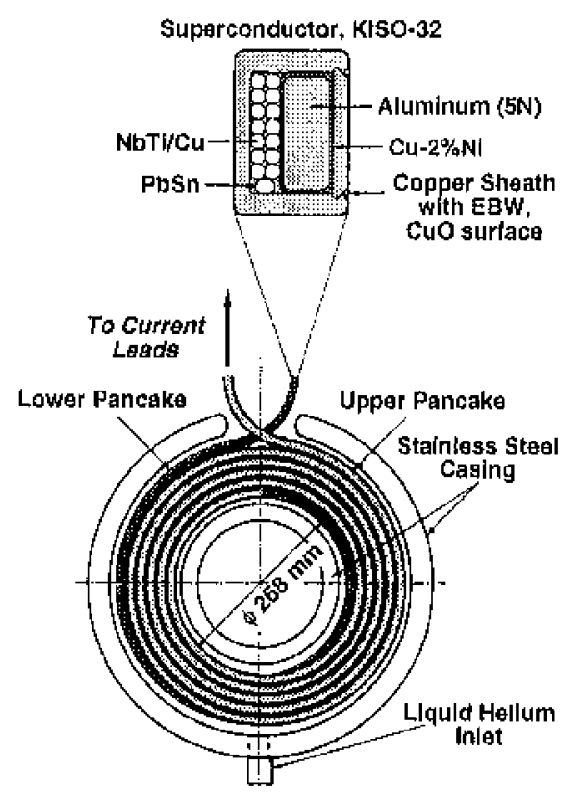

Fig. 2 Schenatic drawing of a double pancake coil, HELJUT. The interal structure ol the superconductor is also shown.

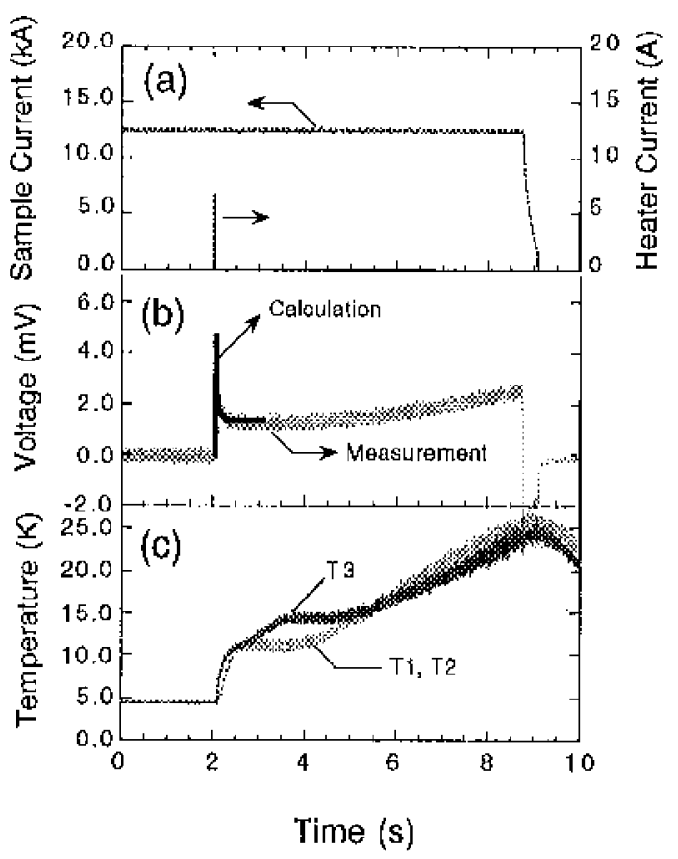

Fig. 3 Typical waveforms of the measured signals on the R\&D coit HELIUT during a stability tost. (a) Transport current and heater power, (b) a longitudinal voltage at the innemost layer with a $126 \mathrm{~mm}$ tap, and (c) conductor surbes temperatures In (b), the thick solid line is given by mumerical simulation.

$[5,6]$ that deteriorates the elfictive magnetoresistivity of aluminum/copper composites and hence the eryogenic stability or the recowery current of the conductor.

The cryogenic stability of this superconductor has been intensively studiad by preparing a number of short samples [7] as well as R\&D coils [8]. A short sample consists of two or foul straight conductors, each $2 \mathrm{~m}$ long and soldered together in series. Fig. 2 illustrates one of the R\&D coils, named HEIJIT, which has double pancake windings (inner radius: $134 \mathrm{nmm}$, outer radius: $227 \mathrm{~nm}$ ), each 5 turns, and a total couductor length of $13 \mathrm{~m}$. Both short samplos and coil samples have been tested in a stperconductor tosi ficility with a $9 \mathrm{~T}$ split-coil, $100 \mathrm{kA}$ current leads, and $75 \mathrm{kA} \mathrm{DC}$ power supplies. The sample conductors were directly cooled by 4.4 $K$ liquid belium and stability tests were perfomed using tiny resistive heaters installed on the conduclor surface to injtiate a notnal zone. The recovery currents and stability margins were measured by changing the bias magnetic field.

Fig. 3 shows a typical cxample of the waveforms of a longitudinal voltage signal as well as temperature signals measured for the R\&D coil IIELIUT. In this case, the maximum. field on the inuermost conductor was $6.8 \mathrm{~T}$ by adding the selffield generated by the sample coil curtent of $12.5 \mathrm{kA}$ to the bias field of $6.4 \mathrm{~T}$. As is seen in Fig. 3(b), after the initiation of a normal zone by the heater power, a longitudinal voltage develops with a short-time excess rise at the beginning of the propagation. This peak voltage seems to be brought on by the magnetic diffusion process in the pure aluminum core. A simple one-dimensional analysis gives a 
time constant of $84 \mathrm{~ms}$ which is fairly close to the measured value of 97 ms determined from the vollage signal,

Fig. 4 shows the dependence of tho measurat propagation velocity of nomal zones on the transport current. Data are taken from some of the shout sample tests as well as the I-HLLIUT wil with the magnetic field of $7 \mathrm{~T}$. One important point found in Fig, 4 is that we observe finite propagation of a nomal zone oven with a transport current lower than the 'cold-end' recovery curtent. In this rogion, an initiated nomal zono develops over a few meters length within a low seconds time and then it ceases to propagate funther and shrinks back to the superconducting statc.

\section{B. Comparivon with Numerical Analysis}

Numerical calculations with sophisticated computer codes have been conducted [9] for solving electromagnetic and thermal processes inside of the present conductor. In tho calculation, degradation of the effoctive resistivity of aluminum/copper composites due to Hall current generation is taken into account with a simple model, and the dynamic current diffusion process into the aluminum core is properly treated. In Fig. 3(b), the longitudinal voltage obtained by the calculation is shown, which givos fiirly good agrement with the measured waveform at the initial phase. Based on this good agreement between the two, it was confimed that the peak voltage can be explained by a current diffusion process into the aluminum core, which transiently reduces the cryogenic stability and hence permits nomal zone propagation, even though the transport current is lower than the steady-state 'cold-end' recovery current. This seems to be a similar phenomenon to that observed for the aluminum stabilized conductor developed for a SMES project [10]. The propagation velocity evaluated by the calculation is indicated in Fig, 4, For the measurement datt, we see a considerable difference in the propagation velocity depending on the propagation direction defined as the up- or ciownstrean side of the transport current. This scems to be related to the Hall voltage generalion, howover; a satisfictory explanation has not yet been made. The calculated propagation velocity lics

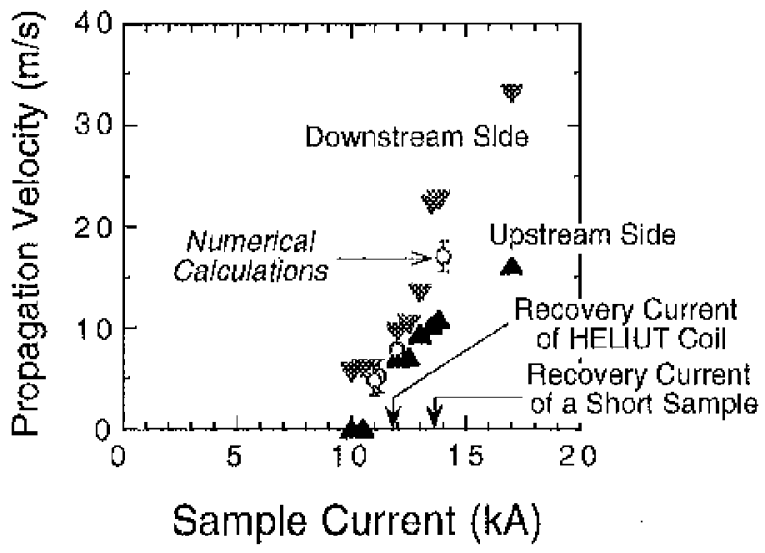

Fig. 4 Propagation velocity of normal zones as a timetion of transport current, measured for short samples atd a coil sample. The dashed line is given by numerical analysis. between the two measured lines. The numerical calculation confims that a finite propagation is possibto oven at a transport current of $9 \mathrm{kA}$.

\section{DISCUSSION}

During the LHD excitation tests, normal transitions in the $\mathrm{H}$ I blocks have been observal five times, including the most severe one shown in Fig. 1. In other cases, the initiated normal zones lasted only br a bew scoonds and recovered, and thus there has been no other quench. The important point is that even for the quench ease, the normal zone initially showed a recovering process. These observations seen to be exactly consistent with our understanding of transiont instability, which was confirned with sample tests.

The cause of triggering the final distuptive transverse propagation that led to the quench of the $\mathrm{H} 1$ coil could be explained by possible deterioration of cooling conditions due to an accumulation of helium bubbles. As is described in [3], from the temperature data of the stainless steet coil-cans, it is inferred that the quenching process stated at one cross-section of the $\mathrm{H} 1$ coil, where it is located below the equatorial plane of the tonis. At this location, the generated holium bubbles may have accumulated atound the innermost layer of the windings where they are positioned at the top roof section in the coil-can. It was estimated that the cooling rate should deteriorate drastically within a fow seconds in the tight channels formed by windings and spacers.

This scenario seems to be supported by the experimental observation of a similar quencli event that we had already experienced with a model superconducting helical coil named TOKI-HB [11] which was tested through the R\&D programs before constructing LIOD. TOKI-HB had one helical coit (major radius: $0.8 \mathrm{~m}$ ) with a helical pitcl number of 3 , which was about $1 / 5$ the size of the LIID helical coils. The composite-type NbTi superconductor (size: $8 \mathrm{~mm} \times 16 \mathrm{~mm}$, nominal current: $8.93 \mathrm{kA}$ at $3.0 \mathrm{~T}$ ) used for the windings had a similar internal structure to that used for the LHD helical coils, but with a conventional copper-clad aluminum stabilizer. A resistive heater of $0.9 \mathrm{~m}$ long was installed inside of the conductor along the aluminum stabllizer at the innemost layer of the windings. $\Lambda$ number of voltage taps were attached on the conductor surface to pick up a normal zone developtnent around the heater area, Fig, 5 shows the stability test results obtained at a transport current of $9.0 \mathrm{kA}$. As is seen in 'ig. 5(a), for the case with an input energy of $280 \mathrm{~W} \times 1 \mathrm{~s}$, the initiated nomal zone completely recovered in about $6 \mathrm{~s}$ atier the termination of the heater energy. On the other land, when the energy input was incrused to $280 \mathrm{~W} \times$ 2 s (Fig. 5(b)), the initiated normal zone could not recover and about $9 \mathrm{~s}$ afer the hoater termination, the neighboring conductors turned into nommal conducting. The important point is that the recovery current of the conductar should be still higher than this transport current as we see no longitudinal propagation of the initiated nomal zone beyond the henter installed region. However, whal had followed was a transverse (turn-to-tum and layer-to-layer) propagation of the nomal zone, as is seen by the voltage development on the neighboring turns. This night be explained when we take 
deterioration of the cooling condition into account. Since the winding structure of the TOKI-IBB helical coil was basically similar to that applied for the LHD helical coils, accumulation of helium bubbles in the interior of the coil-can could also be possible, especially at the position where the helical coil is located below the equatorial plane.

Another example for supporting the scenario of cooling detcrioration is found in the test results of the double pancake R\&D coil, HELIUT. Fig. 3(c) shows the temperature development of the innermost conductor of this coil during a stability test. Cenox sensors were attached on the conductor surfice, $T 1$ and T2 were located above the cquatorial plane, whereas $\mathrm{T} 3$ were at below the equatorial plane. As is seen in Fig. 3(c), although $\mathrm{T} 1$ and $\mathrm{T} 2$ showed temporaly decreases, T3 continuously increased, which might have led to the fill quench of the coil at the end. This phenomenon might also be explained by the deterioration of cooling conditions, especially at the lower part of the coil where it should have an casier condition for accumulating helium bubbles between tight cooling channels in a stainless stecl coil-can. On the contrary, another R\&D coil without a coil-can showed significantly higher recovery currents [8].
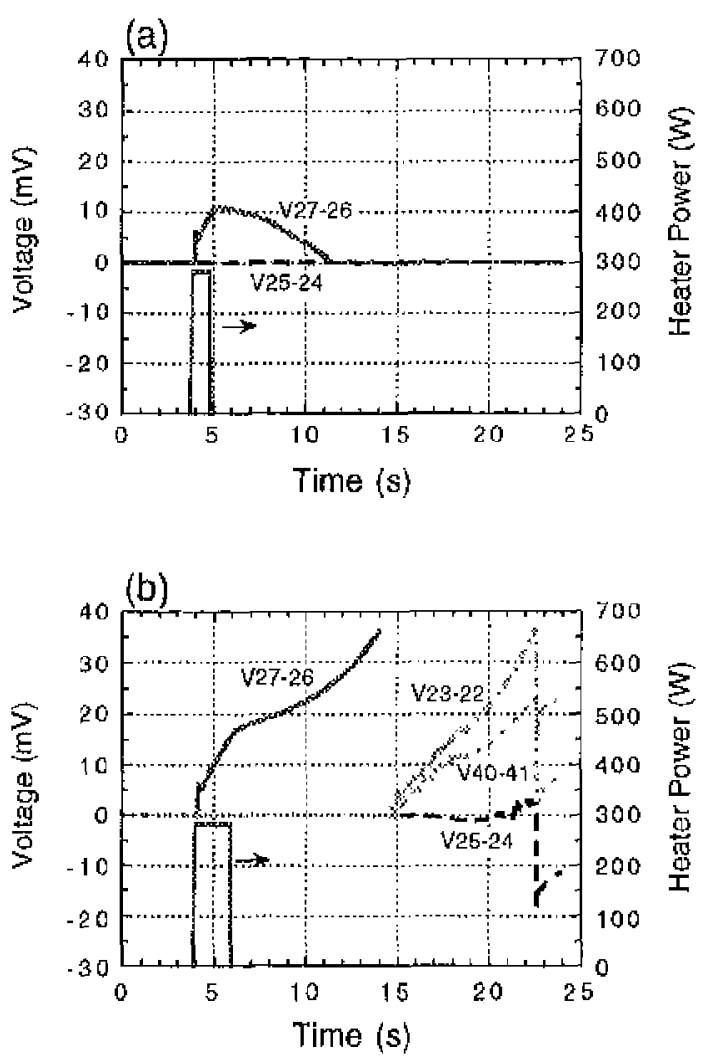

Fig. 5 Voltage signals measured in the R\&D helical coil TOKIHB. (a) $A$ recovery case of a normal zone and (b) a quench case. The voltage 1ap V27-26 covers the heater installed region at the innermost layer of the winding and V25-24 is the neighboring tap on the same turn. Other taps are on difierent lums; V23-22 is on the next turn in the sante layer and V40-41 on the next Iayer.

\section{CONCLUSION}

Normal transitions and a subsequent quench were expericnced by the pool-cooled helical coils of LIID. Stability lests with short samples and R\&D coils confirmed that the conductor could become transiently unstable even though the transport current is lower than the 'cold-end' recovery current. Numerical calculations explained that this is due to the relatively long difusion time constant in the aluminum corc. Although the initiated nomal zone stanted to recover, a disruptive transverse propagation secmed to be triggered for all the blocks of the helical coll, which might be caused by the deterioration of cooling condition with an aceumulation of helium bubbles. This scenario could be supported by the experimental results obtained with an R\&D helical coil as well as by a double pancake coil, both with stainless steel coil-cans. At present, the helical coils steadily supply a toroidal magnetic field of up to $2,75 \mathrm{~T}$ for confining high temperature plasmas in I.IID.

\section{ACKNOWLDGMENTS}

The authors wish to thank all the stafl in NIFS for helping them catry out the LHD excitation tests as well as R\&D experiments. They greatly appreciato the tremendous eflort done by the stafl of Hitachi lutd, and Hitachi Cable l.td. in developing and fibricating the supetconductor, its short samples, the R\&D coils, and the heical coils of LHD.

\section{REFERENCES}

[1] O. Motojima, K. Akaishi, K. Fujii, al al, "Physics and engineeriug design sudies on the Large Helieal Device", Fusion Eng. Des, 20 (1993) pp.3-14.

[2] A, liyoshi, S. Imagnua, the LIID Group, "Design, consiruction and the first operation of '.HD", 20 th Symposimm on Fusion T'ech., (Marseille, 1998).

[3] S. lmagawa, N. Yanagi, I. Chikaraishi, of al., "Results of the first excitation of helical coils of the I arge Helical Device", this conference.

[4] T. Mito, R, Mackawa, A. Iwamolo, ef al " "Per lormance ol the l.HD eryogenic system during cooling and excitation tosts", this conference.

[5] P.W. Fekels, N.C. Iyer, A. Patterson, el al., "Magnetoresistance: the Hall eflect in composite aluminum cryoconductors", Cryogenics 29 (1089) pp. 748-752.

[6] II. Kaneko, N, Yanagi, "Enhancenent of magneto-resistance due to Hall current in alumitum-copper composite", Cryogenies 32 (1992) pp.1114-1120.

[7] N. Yanagi, T. Mito, S. Imagawa, el al., "Development, iabrication, testing and joints of aluminum stabilized superconductors for the helical coils of LHD", Proc ICEC16/ICMC (Kita-Kyushu 1996), pp,751-754.

[8] V.S. Vysotsky, N. Yanagi, Yu,A. Ilyin, et at., "'Pemperature and electric field wistribution measurement inside of the I.IID helical conductor", this conference.

[9] A.V. Gavrilin, N. Yanagi, S. Satoh, O, Motojima, "Computer simulation ol normal zone propagation in the LHD liclical coils", Advances in Supcrcond, XI (1999) pp.1447-1450.

[10] J.M. Plolenhater, M.K. Abdelsalam, F. Botker, el al., "Test results from SMES proof of principle experiment", IEETE Trans Magn. 27 (1991) pp. 1704-1707.

[11] T. Senba, S. Suzuki, T. Masumoto, ol al, "Design and construction of the helical R\&L) coil (TOKI-HB)", Fusion Eng. Dos. 20 (1993) pp.195-200. 